\title{
Growth hormone and the refractoriness of the prepubertal activity system to estradiol in the rat
}

\author{
AL L. PORTERFIELD and JEFFREY J. STERN* \\ University of Michigan, Dearborn, Michigan 48128
}

\begin{abstract}
The relationship between growth hormone $(\mathrm{GH})$ and the inability of estradiol to stimulate running in immature rats was studied using 30 females. Animals were hypophysectomized and ovariectomized at 21 days of age. Starting on Day 25, the females received either 10 micrograms estradiol benzoate (EB) and isotonic saline or 10 micrograms EB and $1 \mathrm{mg}$ bovine GH. The rats administered EB displayed advanced adult running; the females given EB and GH showed prolonged juvenile activity. The results demonstrate that GH contributes to the refractoriness of the prepubertal activity system to estradiol. Estrogen was also found to produce a weight loss and precocious vaginal canalization.
\end{abstract}

The brain mechanisms underlying spontaneous activity and feeding are physiologically similar. Both pathways extend through the hypothalamus and are related to the regulation of body weight (Hetherington \& Ranson, 1940; Brobeck, Tepperman, \& Long, 1943). Activity and feeding show nocturnal and estrous cyclicity (Bunning, 1967). Estradiol influences the behaviors and leads to an overall energy loss (Brobeck, Wheatland, \& Strominger, 1947). The ability of estrogen to alter the behaviors is not seen prepubertally, during pregnancy or pseudopregnancy, or following exogenous progesterone administration (Wade \& Zucker, 1970; Rodier, 1971). Finally, norepinephrine appears to be a neurohumor underlying both systems (Stern \& Zwick, in press).

There is growing evidence that the refractoriness of the prepubertal feeding system to estradiol is due to hypophyseal secretions (see Wade \& Zucker, 1970). Briefly, estrogenic stimulation does not reduce feeding in immature rats. If the animals are hypophysectomized, estrogen limits feeding. Lastly, hypophysectomy reduces food intake in young animals; growth hormone (GH) returns the animals to preoperation eating levels.

The reasons for the refractoriness of the immature activity system are unknown. Given the similarities between the activity and feeding systems and the finding that GH suppresses activity in adult cycling females (Kennedy \& Mitra, 1963), Wade and Zucker (1970) proposed that anterior pituitary hormones render the system refractory. The present study tested and confirmed their suggestion.

\section{METHOD}

The experiments were conducted in a temperature-controlled laboratory with $12 \mathrm{~h}$ of artificial illumination (9:00 a.m.-9:00 p.m.). Standard laboratory rat chow and water were available during all stages of testing.

Pregnant Sprague-Dawley rats were purchased commercially. On the day of parturition (Day 1) litters of 4-6 females were established; on Day 20 the females were weaned. The following

*Send reprint requests to Jeffrey J. Stern. day, 15 females were ovariectomized and hypophysectomized (hereafter referred to as HYPOP-OVX) under pentobarbital anesthesia ${ }^{1}$; the remaining females were sham hypophysectomized and sham ovariectomized (SHAM). In order to obtain 15 HYPOP-OVX animals, it was necessary to operate on a total of 24 females. Immediately following surgery, the females were placed in standard activity wheels with attached living cages. Starting on Day 25 and continuing until Day 60, 5 HYPOP-OVX and 5 SHAM females received 10 micrograms estradiol benzoate (EB groups) $\mathrm{SC}$ in $0.1 \mathrm{ml}$ oil and $0.1 \mathrm{ml}$ saline IP. Five other females from each group received 10 micrograms EB SC and $1 \mathrm{mg}$ bovine growth hormone daily (EB-GH groups). The GH was administered IP in saline immediately following EB administration. The remaining animals received $0.1 \mathrm{ml}$ sesame oil $\mathrm{SC}$ and $0.1 \mathrm{ml} 0.9 \%$ saline IP daily (oil groups).

Revolutions were recorded each morning at approximately 9:00 a.m. Note was taken on the day of complete vaginal canalization. Lastly, the animals were weighed every third morning.

\section{RESULTS}

\section{Activity}

Figure 1 depicts the typical activity pattern of an immature rat (SHAM/OIL). Until 40 days of age, activity is quite low. At about that date, daily running begins to increase ${ }^{2}$ and show cyclicity reaching a peak several months later (not shown in Fig. 1). HYPOP-OVX females without proper hormone replacement display juvenile activity indefinitely (Fig. 2).

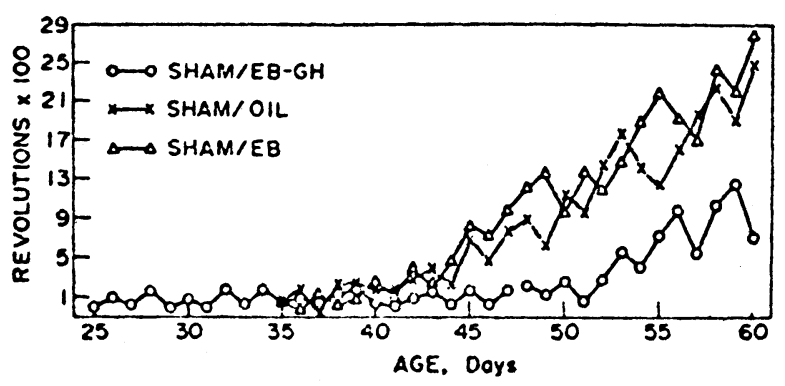

Fig. 1. Daily wheel turns of SHAM females administered 10 micrograms EB and $1 \mathrm{mg}$ bovine $\mathrm{GH}$, oil, or 10 micrograms EB. 


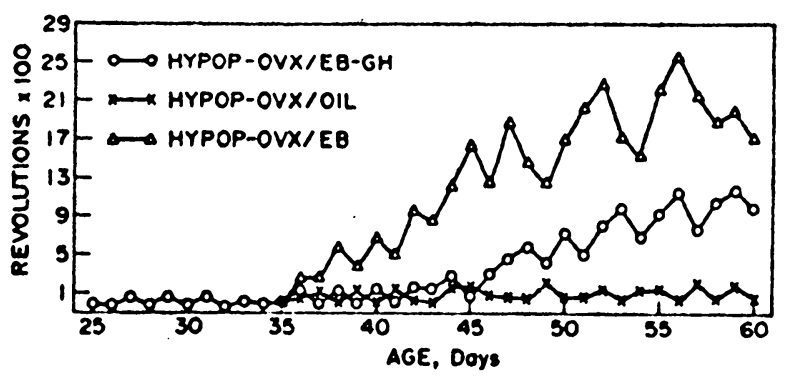

Fig. 2. Daily activity of hypophysectomized and ovariectomized animals administered EB and GH, oil, or EB.

Estradiol did not advance the first appearance of adult running in intact females. The five SHAM/EB animals first displayed higher activity during Days 37-45 (Fig. 1). Once running increased, however, estradiol had a stimulating effect. By Day 50 the SHAM/EB females were running significantly more than the SHAM/OIL animals ( $p<.05$ Mann-Whitney U test). In HYPOP-OVX animals, estradiol both advanced and stimulated spontaneous activity. The HYPOP-OVX/EB group first increased running during Days 32-36 and during Days 40-50 ran significantly more than the HYPOP-OVX/OIL females ( $p<.01$; Fig. 2 ).

Growth hormone given with EB delayed the first appearance of increased activity. In the SHAM/EB-GH group, running was not elevated until Days 52-55; in the HYPOP-OVX/EB-GH group, not until Days 44-57. Of interest is the finding that under both conditions, spontaneous activity rose even though the animals continued to receive $\mathrm{GH}$. In addition, $\mathrm{GH}$ inhibited the activating effects of EB. During Days 45-50, the animals administered EB and GH ran significantly less than the animals given $E B$ and saline $(p<.01)$.

\section{Body Weight}

On Day 22 when records were first taken, the groups did not differ with respect to body weight. The SHAM females continued to have equivalent body weights until Day 40. At this point the SHAM/EB females began to show reduced body weight relative to SHAM/OIL animals (Fig. 3 ). The difference between the groups first became significant on Day 46 and persisted until Day 60. In contrast, following Day 40 the SHAM/EB-GH females began to show heavier body weights. While the difference between these animals and the SHAM/OIL group never reached significance, a trend is evident (Fig. 3).

The HYPOP-OVX females continued to gain weight following surgery (Fig. 4). At about Day 31, however, the females given oil or estradiol began to display reduced growth. By Day 34 these females weighed significantly less than the HYPOP-OVX animals given EB and $\mathrm{GH}$. The difference was observed throughout testing. As a group the HYPOP-OVX rats weighed less than the SHAM group $(\mathrm{p}<.01)$.

\section{Vaginal Canalization}

Vaginal opening was markedly influenced by estradiol. The SHAM/OIL females showed complete vaginal canalization on Day 39 (range, 38-41). Estradiol advanced vaginal opening in all groups (i.e., SHAM, HYPOP-OVX, EB, or $\mathrm{EB}+\mathrm{GH}$ ) to $\overline{\mathrm{X}}=35$ days (range, 33-36). The HYPOP-OVX animals never displayed complete canalization.

\section{DISCUSSION}

The present data clearly demonstrate that growth hormone contributes to the refractoriness of the juvenile activity system to estradiol. The decline in $\mathrm{GH}$ secretion during Days 40-50 (Frohman \& Bernardis, 1968) coincident with the elevation in estradiol titers (Smith \& Davidson, 1968), therefore, can be viewed as a major factor underlying the increased running at puberty. The finding that females given EB and $\mathrm{GH}$ do eventually display higher levels of running (Fig. 2) suggests a second

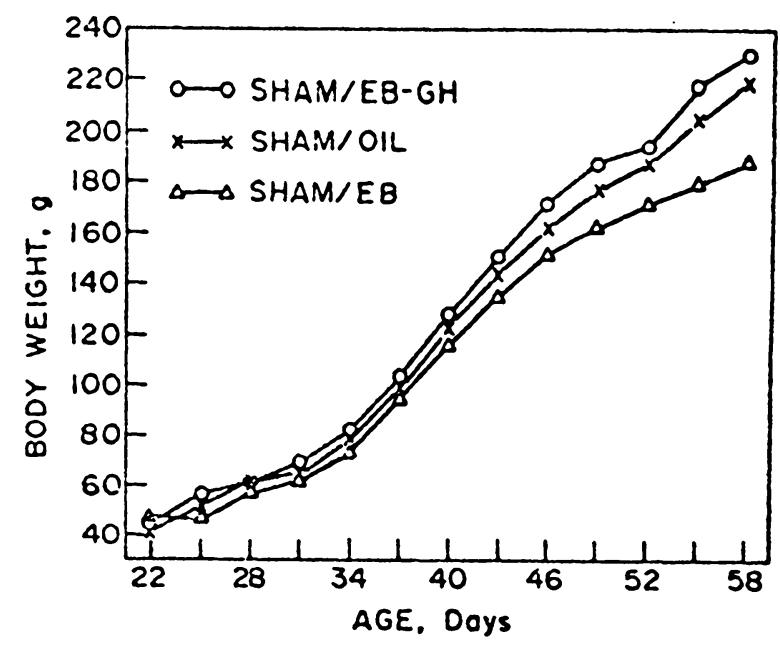

Fig. 3. Body weights taken in grams every 3 days of the SHAM females.

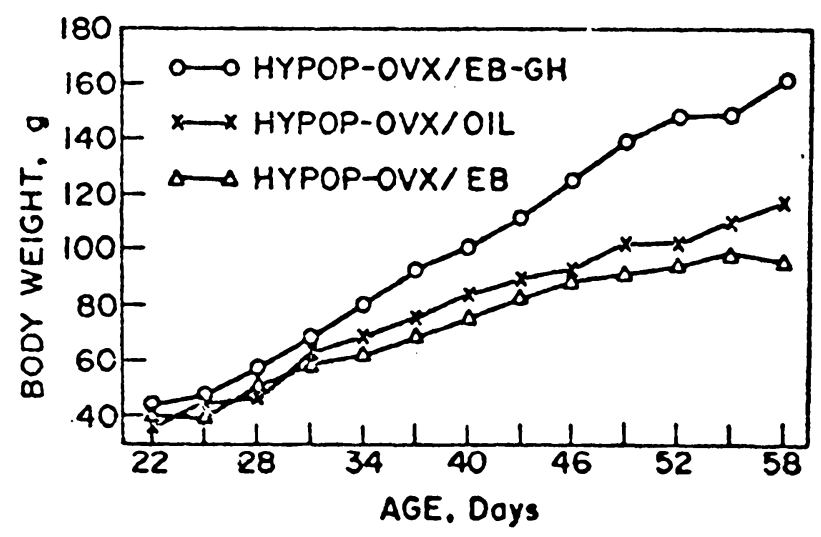

Fig. 4. Body weights recorded every 3 days in grams of the HYPOP-OVX animals. 
factor. Perhaps the neural substrate for running becomes hypersensitive to estradiol at about 45 days. It is noteworthy that during this same period, the neural centers controlling gonadotropin release show altered sensitivity to estradiol (Ramirez \& McCann, 1963).

The stimulating effects of estradiol on spontaneous wheel running are well documented (Young \& Fish, 1945; Stern \& Jankowiak, in press). Recently, Wade (1972) suggested that the actions of EB may not be on the activity "center" directly, but rather on the pituitary. The pituitary would then influence activity directly or indirectly via other glands. However, the present findings and those of Stern and Jankowiak (in press) demonstrate that estradiol's effect is independent of the hypophysis.

Estradiol produced a decrease in body weight (Fig. 3). Given the catabolic actions of estrogen (Aschkenasy-Lelu \& Aschkenasy, 1959) and the lack of food intake data, it is possible that the observed effect was independent of the CNS. Alternatively, estradiol may have lowered the setting of a central homeostat that dictates the animal's body weight (see Mook, Kenney, Roberts, Nussbaum, \& Rodier, 1972; Stern, Porterfield, \& Krupa, in press). Under this theory, changes in feeding are viewed as secondary adjustments to an altered set point. The present data are seen as a further demonstration of this phenomenon.

While GH inhibited the actions of EB on activity, it did not prevent the effects on peripheral tissue (vaginal canalization). This finding is reminiscent of the data on cyproterone acetate and running (Stern \& Murphy, 1971). Testosterone increases spontaneous activity in castrated males. Cyproterone acetate administered with the androgen prevents the rise in activity but does not inhibit the stimulating actions of $\mathrm{Tp}$ on seminal vesicle weight.

Temperature regulation like food intake and running is weight regulatory (see Wade, 1972). During proestrus with its elevated estrogen titers, there is a drop in body temperature of $1^{\circ} \mathrm{C}$ (McLean \& Coleman, 1971). Also, Nieburgs and Greenblatt (1948) indicate that in ovariectomized rats, estrogen lowers body temperature. It would be of interest to know the effects of EB and $\mathrm{GH}$ on thermoregulation in the immature rat.

\section{REFERENCES}

Aschkenasy-Lelu, P., \& Aschkenasy, A. Effects of androgens and oestrogens on the metabolism of proteins and the growth of tissues. World Review of Nutrition \& Dietetics, 1959, 1, 33-60.

Brobeck, J. R., Tepperman, J., \& Long, C. N. H. Experimental hypothalamic hyperphagia in the albino rat. Yale Journal of Biology \& Medicine, 1943, 15, 831-851.

Brobeck, J. R., Wheatland, M., \& Strominger, J. L. Variations in regulation of energy exchange associated with estrus, diestrus and pseudopregnancy in rats. Endocrinology, 1947, 40, 65-72.

Bunning, E. The physiological clock. New York: Springer-Verlag, 1967.

Frohman, L. A., \& Bernardis, L. L. Growth hormone and insulin levels in weaning rats with ventromedial hypothalamic lesions. Endocrinology, 1968, 82, 1125-1132.

Hetherington, A. W., \& Ranson, S. W. Hypothalamic lesions and adiposity in the rat. Anatomical Record, 1940, 78, 149-172.

Kennedy, G. C., \& Mitra, J. Hypothalamic control of energy balance and the reproductive cycle in the rat. Journal of Physiology, 1963, 166, 395-407.

McLean, J. H., \& Coleman, W. P. Temperature variation during the estrous cycle: Active vs restricted rats. Psychonomic Science, 1971, 22, 179-180.

Mook, D. G., Kenney, N. J., Roberts, S., Nussbaum, A. I., \& Rodier, W. I. Ovarian-adrenal interactions in regulation of body weight by female rats. Journal of Comparative \& Physiological Psychology, 1972, 81, 198-211.

Nieburgs, H. E., \& Greenblatt, R. B. The role of the endocrine glands in body temperature regulation. Journal of Clinical Endocrinology, 1948, 8, 622-623.

Ramirez, U. D., \& McCann, S. M. Comparison of the regulation of luteinizing hormone ( $\mathrm{LH})$ secretion in immature and adult rats. Endocrinology, 1963, 72, 452-464.

Rodier, W. I., III. Progesterone-estrogen interactions in the control of activity-wheel running in the female rat. Journal of Comparative \& Physiological Psychology, 1971, 74, 365-373.

Smith, E. R., \& Davidson, J. M. Role of estrogen in the cerebral control of puberty in female rats. Endocrinology, 1968, 82, 100-108.

Stern, J. J., \& Jankowiak, R. No effect of neonatal estrogenic stimulation or hypophysectomy on spontaneous activity in female rats. Journal of Comparative \& Physiological Psychology, in press.

Stern, J. J., \& Murphy; M. The effects of cyproterone acetate on the spontaneous activity and seminal vesicle weight of male rats. Journal of Endocrinology, 1971, 50, 441-443.

Stern, J. J., Porterfield, A. L., \& Krupa, R. J. Endocrine interactions in regulation of body weight by female rats. Journal of Comparative \& Physiological Psychology, in press.

Stern, J. J., \& Zwick, G. Effects of intraventricular norepinephrine and estradiol benzoate on weight regulatory behavior in female rats. Behavioral Biology, in -prëss. e-

Wade, G. N. Gonadal hormones and behavioral regulation of body weight. Physiology \& Behavior, 1972, 8, 523-5.34. .

Wade, G. N., \& Zucker, I. Development of hormönal control over food intake and body weight in female rats. Journal of Comparative \& Physiological Psychology, 1970, 70, 213-220.

Young, W. C., \& Fish, W. R. The ovarian hormones and spontaneous running activity in the female rat. Endocrinology, 1945, 36, 181-189.

\section{NOTES}

1. The surgery was performed by Donald G. Anderson.

2. No operational definition of increased activity was employed. However, visual examination of, an activity chart makes determination of this measure straightforward and reliable.

(Received for publication July 31, 1973; accepted September 6, 1973.) 